\title{
COMMENTARY
}

\section{Autophagy-Based Diagnosis of Pregnancy Hypertension and Pre-Eclampsia}

Surendra Sharma

From the Department of Pediatrics, Women and Infants Hospital, Warren Alpert Medical School of Brown University, Providence, Rhode Island

In this issue of The American Journal of Pathology, Aoki et $\mathrm{al}^{1}$ present evidence that placental Atg7 deficiency in conditional Atg7 knockout mice may cause pregnancyassociated hypertension, a primary diagnostic feature of pre-eclampsia. Pre-eclampsia is a major complication of pregnancy that is diagnosed by de novo onset of hypertension often with proteinuria after 20 weeks of gestation and affects $5 \%$ to $8 \%$ pregnancies with higher incidence in low resource settings. ${ }^{2-9}$ It is a leading cause of maternal and fetal morbidity and mortality and represents a pivotal risk factor for chronic diseases, including cardiovascular disease, diabetes mellitus, and renal disease. ${ }^{2-9}$ This devastating pregnancy disorder is associated with multi-organ injury and on the fetal side, is invariably complicated with fetal growth restriction. Although the etiology of pre-eclampsia, particularly pregnancy hypertension and end organ injury, is still poorly understood, it is widely accepted that poor placentation coupled with local and systemic inflammation is the major causative factor. At the maternal-fetal interface, several detrimental events including defective spiral artery remodeling, hypoxia/ischemia microenvironment, reperfusion injury, and excessive production of pregnancyincompatible factors such as anti-angiogenic factors, inflammatory cytokines, and alarmins are well documented. ${ }^{7-10}$ The circulating factors are thought to program the onset of hypertension and other pre-eclampsia-like features. What may lead to poor placentation? Recently, presence of toxic protein aggregates in the placenta as well as in serum and urine has been demonstrated. ${ }^{11-13}$ These protein aggregates can also be part of the placental exosome cargo and can be induced in human trophoblasts by hypoxia or inflammatory cytokines. ${ }^{14}$ Importantly, they cause trophoblast cell death and induce pre-eclampsia-like pathology in pregnant mice. ${ }^{11}$ Why these protein aggregates not cleared from the placenta? Autophagy is a mechanism inside a cell that degrades damaged organelles and proteins for reuse. ${ }^{15,16}$ However, overwhelming environmental factors and/or intracellular stress may impair autophagy by inducing excessive toxic protein aggregation or damage beyond repair. In this regard, numerous studies have established a relationship between autophagy and various human diseases, particularly neurodegenerative diseases. ${ }^{15,16}$ It is unclear if the presence of protein aggregates in hypertensive pre-eclampsia syndrome a result of impaired autophagy.

\section{Autophagy and ATG7}

Prof. Yoshinori Ohsumi, who received the 2016 Noble Prize in Physiology or Medicine on his work on autophagy, recently provided a chronological description of historical research landmarks on autophagy. ${ }^{17}$ According to him, the year of 2013 marked the 50th anniversary of Christian de Duve's coining of the term "autophagy" for the degradation process of cytoplasmic constituents. In other words, autophagy is a lysosome-mediated intracellular bulk or selective degradation system to remove toxic macromolecules and organelles, thus maintaining cellular homeostasis and metabolism. Autophagy has been described to be a regulatory mechanism in all cellular organisms, including yeast, and regulates cellular growth and differentiation, remodeling and health, adaptation to stress, control or propagation of viral infections, and tumor suppression. The number of

Supported in part by the NIH Research Grant P20 GM121298.

Accepted for publication September 7, 2018.

Disclosures: None declared.

Address correspondence to Surendra Sharma, M.D., Ph.D., Department of Pediatrics, Women and Infants Hospital, 101 Dudley St., Providence, RI 02905. E-mail: ssharma@wihri.org 


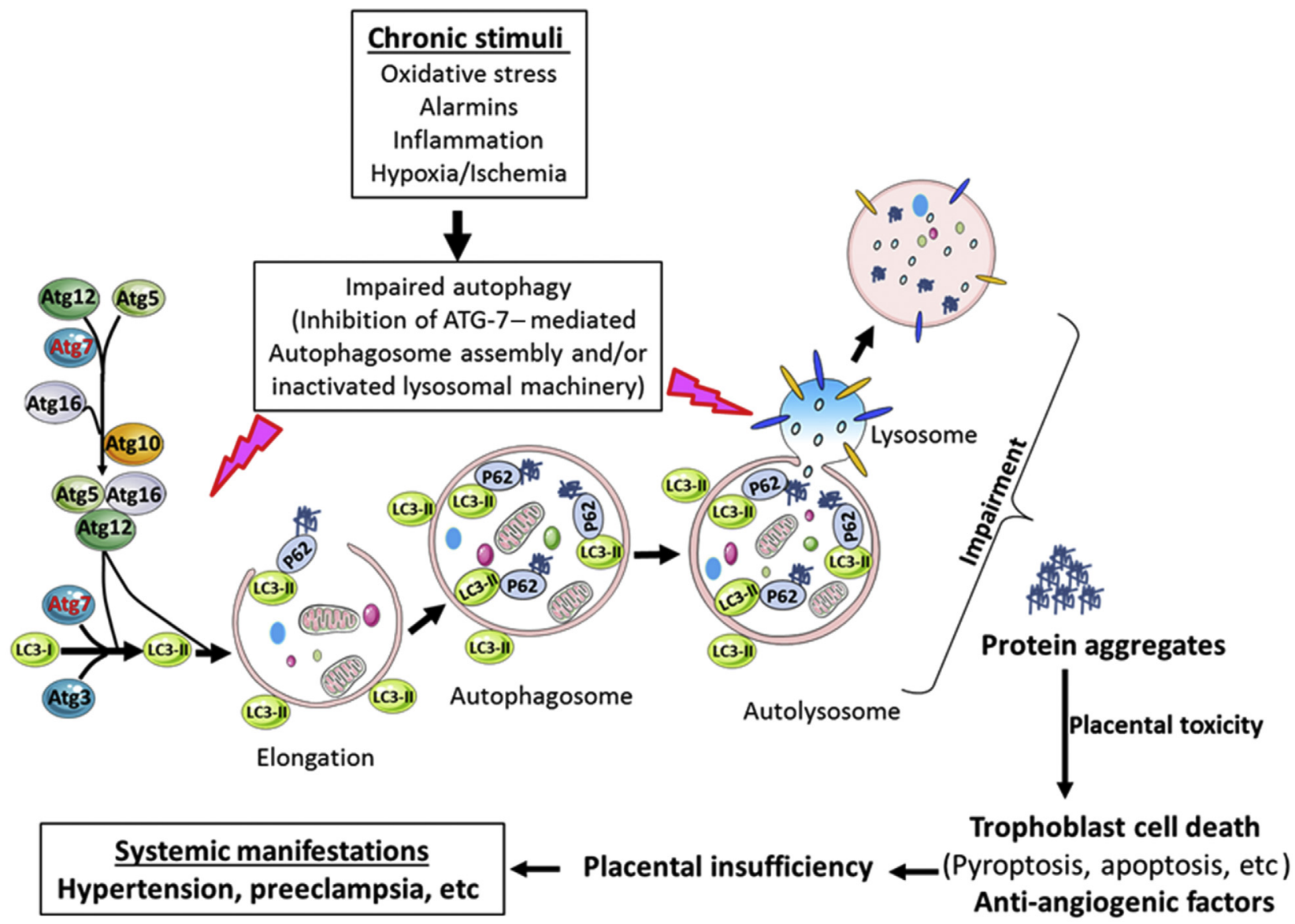

Figure 1 Schematic diagram showing the role of ATG7-like protein in the autophagy machinery and the effect of its deficiency on placentation and programming of pregnancy complications such as preeclampsia.

research articles on autophagy has ballooned up exponentially by the year 2013 and continues to grow. ${ }^{17}$ The autophagy-related genes (ATG) have been characterized and now the number of these genes has increased to 37 , involved in the core machinery of the autophagosome assembly and in the selective modes of autophagy. ${ }^{16}$ The ATG proteins involved in the autophagosome assembly are made up of several functional units. Several functional combinations of ATG proteins are involved in regulating autophagy. ${ }^{18}$ These systems mostly work in concert as ATG7, ATG3, and ATG5 complexed with ATG12 and ATG16 are required for the ATG8-phosphatydylethanolamine conjugation system (Figure 1). This complex and highly choreographed regulatory machinery of autophagy is required to maintain cellular health. The mechanisms of action of ATG proteins have been partially studied using knockout mouse models involving individual ATG genes. For example, ATG7 deficiency results in fetal death just after delivery and its liver-specific deficient mice exhibit p62 accumulation in the cytoplasm of hepatocytes. ${ }^{19}$ The p62 protein serves as a substrate of autophagy and presents ubiquitin-conjugated proteins to the phagophore. Deletion of ATG7 in the central nervous system results in neuron death and abnormal limb reflexes. ${ }^{20}$ Thus, deficiency of the ATG genes may affect different organs and lead to fatal consequences due to energy depletion, accumulation of protein aggregates, and metabolic stress. Our knowledge of the role of autophagy and its related genes is still limited. Since ATG gene deficiency could be lethal, one way to study its specific effects is to generate conditional knockout strains. In the article by Aoki et al, ${ }^{1}$ the authors have used such an approach to study the role of ATG7 in the placenta and to correlate it with pregnancy complications such as hypertension and pre-eclampsia.

\section{Autophagy, Placenta, and Pregnancy}

It has been proposed that autophagy acts as a guard to the placenta against pathogens and stress. ${ }^{21,22}$ Curiously, placental autophagy can also be exploited by pathogens to evade surveillance from host defenses. ${ }^{23}$ Several reports have also suggested that autophagy is hyper-activated in the placenta of women diagnosed with pre-eclampsia. ${ }^{24,25}$ However, excessive autophagy may not explain why there is placental accumulation of protein aggregates in pre-eclampsia. It was unclear if placenta-specific conditional Atg7 deficiency causes pre-eclampsia-like features in 
pregnant dams, including elevated blood pressure (hypertension), proteinuria, fetal growth restriction, placental hypoxic injury, and glomerular endotheliosis. Aoki et $\mathrm{al}^{1}$ present data that suggest that in conditional mice (Atg7cKO), there was placental-, not fetal-, specific accumulation of p62. Atg7cKO mice showed elevated blood pressure during pregnancy, reduced levels of placental growth factor, and small placenta. Importantly, Atg $7 \mathrm{cKO}$ mice showed poor trophoblast invasion and apoptosis as compared to control EGFP mice, critical features observed in the placenta of pre-eclampsia deliveries. Although Atg $7 \mathrm{cKO}$ mice do not experience the severe pathological features of pre-eclampsia, it is possible that other factors in addition to ATG7 contribute to the onset of severe preeclampsia pathology. For example, Illo KO mice exhibit full spectrum pre-eclampsia-like features compared to their wild-type counterparts, suggesting that IL-10 provides partial protective effects. ${ }^{26}$ It will be interesting to see the status of protein aggregates in the placenta of $A \operatorname{tg} 7 \mathrm{cKO}$ mice for better understanding of the placental pathology. Another important question that arises in the context of partial pathology of pre-eclampsia-like features in Atg7cKO mice is whether the Atg7 deficiency is total or partial. In the article by Aoki et al, ${ }^{1}$ trophoblast-specific conditional $\operatorname{Atg} 7^{-1-}$ mice are shown to exhibit significant elevation in blood pressure (hypertension), reduced expression of placental growth factor, and smaller placenta with no changes in proteinuria and fetal growth restriction. This raises an important question whether combination of deficiency in another ATG gene as well as Atg7 will result in the full spectrum of severe pathology of pre-eclampsia.

\section{Autophagy-Based Diagnosis and Treatment}

The chronic exposure to detrimental triggers may induce protein aggregation and cause impaired autophagy, resulting in placental toxicity and trophoblast cell death and eventually placental insufficiency (Figure 1). Thus early detection of protein aggregates in serum using autophagy-deficient trophoblast cells can be used as a diagnostic tool. Poor placentation due to autophagy deficiency may further lead to production of anti-angiogenic factors, inflammatory cytokines, cell-free DNA, and extracellular vesicles to program systemic manifestation of hypertension and endothelium dysregulation. Taken together, a therapeutic strategy can be proposed based on inhibition of protein aggregation and autophagy restoration.

\section{References}

1. Aoki A, Nakshima A, Kusabiraki T, Ono Y, Yoshino O, Muto M, Kumasawa K, Yoshimori T, Ikawa M, Saito S: Trophoblast-specific conditional ATG7 knockout mice develop gestational hypertension. Am J Pathol 2018, 188:2474-2486
2. Sibai B, Dekker G, Kupferminc M: Pre-eclampsia. Lancet 2005, 365 : 785-799

3. Wildman K, Bouvier-Colle MH: Maternal mortality as an indicator of obstetric care in Europe. BJOG 2004, 111:164-169

4. Cheng S-B, Sharma S: Preeclampsia and health risks later in life: an immunological link. Semin Immunopathol 2016, 38:699-708

5. Vikse BE, Irgens LM, Leivestad T, Skjaerven R, Iversen BM: Preeclampsia and the risk of end-stage renal disease. N Engl J Med 2008, 359:800-809

6. Smith GC, Pell JP, Walsh D: Pregnancy complications and maternal risk of ischaemic heart disease: a retrospective cohort study of 129,290 births. Lancet 2001, 357:2002-2006

7. Roberts JM, Hubel CA: Is oxidative stress the link in the two stage model of preeclampsia? Lancet 1999, 354:788-789

8. Redman CW, Sacks GP, Sargent IL: Preeclampsia: an excessive maternal inflammatory response to pregnancy. Am J Obstet Gynecol 1999, 180:499-506

9. Burton GJ, Yung HW: Endoplasmic reticulum stress in the pathogenesis of early-onset pre-eclampsia. Pregnancy Hypertens 2011, 1:72-78

10. Levine RJ, Maynard SE, Qian C, Lim KH, England LJ, Yu KF, Schisterman EF, Thadhani R, Sachs BP, Epstein FH, Sibai BM, Sukhatme VP, Karumanchi SA: Circulating angiogenic factors and the risk of preeclampsia. N Engl J Med 2004, 350:672-683

11. Kalkunte SS, Neubeck S, Norris WE, Cheng SB, Kostadinov S, Vu Hoang D, Ahmed A, von Eggeling F, Shaikh Z, Padbury J, Berg G, Olofsson A, Markert UR, Sharma S: Transthyretin is dysregulated in preeclampsia, and its native form prevents the onset of disease in a preclinical mouse model. Am J Pathol 2013, 183:1425-1436

12. Buhimschi IA, Nayeri UA, Zhao G, Shook LL, Pensalfini A, Funai EF, Bernstein IM, Glabe CG, Buhimschi CS: Protein misfolding, congophilia, oligomerization, and defective amyloid processing in preeclampsia. Sci Transl Med 2014, 6:245ra92

13. McCarthy FP, Adetoba A, Gill C, Bramham K, Bertolaccini M, Burton GJ, Girardi G, Seed PT, Poston L, Chappell LC: Urinary congophilia in women with hypertensive disorders of pregnancy and preexisting proteinuria or hypertensin. Am J Obstet Gynecol 2016, 215:464.e1-464.e7

14. Tong M, Cheng SB, Chen Q, DeSousa J, Stone PR, James JL, Chamley LW, Sharma S: Aggregated transthyretin is specifically packaged into placental nano-vesicles in preeclampsia. Sci Rep 2017 $7: 6694$

15. Mizushima N, Levine B, Cuervo AM, Klionsky DJ: Autophagy fights disease through cellular self-digestion. Nature 2008, 451:1069-1075

16. Nakatogawa H, Suzuki K, Kamada Y, Ohsumi Y: Dynamics and diversity in autophagy mechanisms: lessions from yeast. Nat Rev Mol Cell Biol 2009, 10:458-467

17. Ohsumi Y: Historical landmarks of autophagy research. Cell Res 2014, 24:9-23

18. Yamaguchi J, Suzuki C, Nano T, Kakuta S, Ozawa K, Tanida I, Saitoh T, Sunabori T, Komatsu M, Tanaka K, Aoki S, Sakimura K, Uchiyama Y: Atg9a deficiency causes axon-specific lesions including neuronal circuit dysgenesis. Autophagy 2018, 14:764-777

19. Komatsu M, Waguri S, Koike M, Sou YS, Ueno T, Hara T, Mizushima N, Iwata J, Ezaki J, Murata S, Hamazaki J, Nishito Y, Iemura S, Natsume T, Yanagawa T, Uwayama J, Warabi E, Yoshida H, Ishii T, Kobayashi A, Yamamoto M, Yue Z, Uchiyama Y, Kominami E, Tanaka K: Homeostatic levels of p62 control cytoplasmic inclusion body formation in autophagy-deficient mice. Cell 2007, 131:1149-1163

20. Komatsu M, Wang QJ, Holstein GR, Friedrich VL, Iwata J, Kominami E, Chait BT, Tanaka K, Yue Z: Essential role for autophagy protein Atg7 in the maintenance of axonal homeostasis and the prevention of axonal degeneration. Proc Natl Acad Sci U S A 2007, 104: 14489-14494

21. Delorme-Axford E, Donker RB, Mouillet JF, Chu T, Bayer A, Ouyang Y, Wang T, Stolz DB, Sarkar SN, Morelli AE, 
Sadovsky Y, Coyne CB: Human placental trophoblasts confer viral resistance to recipient cells. Proc Natl Acad Sci U S A 2013, 110: $12048-12053$

22. Hung TH, Hsieh TT, Chen SF, Li MJ, Yeh YL: Autophagy in the human placenta throughout gestation. PLoS One 2013, 8:e83475

23. Cao B, Parnell LA, Diamond MS, Mysorekar IU: Inhibition of autophagy limits vertical transmission of Zika virus in pregnant mice. J Exp Med 2017, 214:2303-2313

24. Gao L, Qui HB, Kamana KC, Zhang XM, Zhang H, Baker PN: Excessive autophagy induces the failure of trophoblast invasion and vasculature: possible relevance to the pathogenesis of preeclampsia. J Hypertens 2015, 33:106-117

25. Melland-Smith M, Ermini L, Chauvin S, Craig-Barnes $H$, Tagliaferro A, Todros T, Post M, Caniggia I: Disruption of sphingolipid metabolism augments ceramide-induced autophagy in preeclampsia. Autophagy 2015, 11:653-669

26. Kalkunte S, Boij R, Norris W, Friedman J, Lai Z, Kurtis J, Lim KH, Padbury JF, Matthiesen L, Sharma S: Sera from preeclampsia patients elicit symptoms of human disease in mice and provide a basis for an in vitro predictive assay. Am J Pathol 2010, 177:2387-2398 